\title{
HIMPUNAN LEMBUT KABUR INTUISIONISTIK HESITANT BERNILAI INTERVAL
}

\author{
SELVI AIDIA PUTRI \\ Program Studi S1 Matematika, \\ Fakultas Matematika dan Ilmu Pengetahuan Alam, Universitas Andalas, \\ Kampus UNAND Limau Manis Padang, Indonesia. \\ email : aidiaselvi@gmail.com
}

Diterima 9 Maret 2019 Direvisi 7 April $2019 \quad$ Dipublikasikan 7 Mei 2019

\begin{abstract}
Abstrak. Teori himpunan kabur pertama kali diperkenalkan oleh Prof.L.A.Zadeh pada tahun 1965. Teori ini memuat unsur ketidakpastian dan kekaburan suatu permasalahan. Oleh karena itu, pada tahun 1999 diperkenalkan teori himpunan lembut, yang mana teori ini berguna untuk menyelesaikan masalah yang mengandung unsur ketidakpastian dan keragu-raguan. Seiring dengan perkembangan zaman, masalah yang akan dihadapi semakin rumit. Oleh karena itu, diperkenalkan suatu teori baru yaitu himpunan lembut kabur intuisionistik hesitant bernilai interval. Pada tulisan ini akan dibahas tentang beberapa definisi yang berkaitan dengan himpunan lembut kabur intuisionistik hesitant bernilai interval beserta operasi-operasi dan sifat-sifatnya.
\end{abstract}

Kata Kunci: Himpunan Kabur, Himpunan Lembut, Himpunan Lembut Kabur Intuisionistik Hesitant Bernilai Interval

\section{Pendahuluan}

Himpunan kabur pertama kali diperkenalkan oleh Prof.L.A.Zadeh pada tahun 1965. Pada tahun 1999, Molodstov memperkenalkan suatu teori himpunan lembut yang digunakan untuk mengatasi masalah yang mengandung unsur ketidakpastian dan kekaburan pada himpunan kabur. Kajian tentang himpunan kabur dan himpunan lembut terus berlanjut, diantaranya teori himpunan kabur intuisionistik yaitu himpunan kabur yang memiliki derajat keanggotaan dan derajat ketidakanggotaan yang berada pada selang $[0,1]$, teori himpunan lembut kabur intuisionistik, teori himpunan kabur hesitant yaitu himpunan kabur yang memiliki derajat keanggotaan yang berbeda-beda pada selang $[0,1]$, dan untuk masalah yang lebih rumit Yong Yang memperkenalkan suatu teori baru yang dinamakan dengan teori himpunan lembut kabur intuisionistik hesitant bernilai interval. Teori ini merupakan penggabungan antara teori himpunan kabur intuisionistik hesitant bernilai interval dan teori himpunan lembut. Pada tulisan ini akan dibahas sifat-sifat aljabar yang terkait dengan himpunan lembut kabur intuisionistik hesitant bernilai interval seperti operasi gabungan, irisan, hukum De Morgan, dan sebagainya. 


\section{Tinjauan Pustaka}

Beberapa Definisi dan Teorema yang akan digunakan pada tulisan ini.

Definisi 2.1. [1] Misalkan X adalah himpunan semesta. Himpunan kabur intuisionistik bernilai interval $\tilde{A}$ atas $X$, dan dapat dinyatakan dalam bentuk:

$$
\widetilde{A}=\left\{\left\langle x, \mu_{\widetilde{A}}(x), \nu_{\widetilde{A}}(x)\right\rangle \mid x \in X\right\},
$$

dimana $\mu_{\tilde{A}}: X \rightarrow \operatorname{int}[0,1]$ dan $\nu_{\tilde{A}}: X \rightarrow \operatorname{int}[0,1]$ berturut-turut menyatakan derajat keanggotaan dan derajat ketidakanggotaan dari $x \in X$ pada himpunan $\tilde{A}$, dan int $[0,1]$ merupakan himpunan dari seluruh subinterval tertutup pada interval $[0,1]$.

$\mathrm{Xu}$ [2] mendefinisikan suatu bilangan kabur intuisionistik bernilai interval (IVIFN) sebagai suatu pasangan terurut $\left(\mu_{\tilde{A}}(x), \nu_{\tilde{A}}(x)\right)$. Secara sederhana, IVIFN dapat ditulis dalam bentuk $\alpha=\left(\mu_{\alpha}, \nu_{\alpha}\right)$ dengan $\mu_{\alpha}=\mu_{\widetilde{A}}=\left[\mu_{\alpha}^{-}, \mu_{\alpha}^{+}\right]$, dan $\nu_{\alpha}=\nu_{\widetilde{A}}$ $=\left[\nu_{\alpha}^{-}, \nu_{\alpha}^{+}\right]$.

Definisi 2.2. [4] Misalkan $X$ adalah himpunan semesta. Himpunan kabur hesitant bernilai interval $\widetilde{I}$ atas $X$ dapat ditulis dalam bentuk:

$$
\widetilde{I}=\left\{\left\langle x, h_{\widetilde{I}}(x)\right\rangle \mid x \in X\right\},
$$

dimana $h_{\widetilde{I}}(x)$ adalah himpunan dari beberapa subinterval yang berbeda pada interval $[0,1], h_{\widetilde{I}}(x)$ juga menotasikan derajat keanggotaan dari $x \in X$ pada himpunan $\tilde{I}$.

Definisi 2.3. [4] Misalkan U adalah himpunan semesta. Himpunan kabur hesitant bernilai interval $\widetilde{E}$ atas $X$ dapat ditulis dalam bentuk:

$$
\widetilde{E}=\left\{\left\langle x, h_{\widetilde{E}}(x)\right\rangle \mid x \in U\right\},
$$

dimana $h_{\widetilde{E}}(x)$ adalah himpunan dari beberapa bilangan kabur intuisionistik bernilai interval (IVIFN). $h_{\widetilde{E}}(x)$ menotasikan interval derajat keanggotaan dan interval derajat ketidakanggotaan dari $x \in U$ pada himpunan $\widetilde{E}$, dan $h_{\widetilde{E}}(x)$ juga dapat disebut sebagai elemen kabur intuisionistik hesitant bernilai interval (IVIHFE).

Zhang [4] mendefinisikan $\tilde{h}=h_{\widetilde{E}}(x)$ sebagai suatu elemen kabur intuisionistik hesitant bernilai interval (IVIHFE). Himpunan dari seluruh himpunan kabur intuisionistik hesitant bernilai interval atas $\mathrm{U}$ dinotasikan dengan $\tilde{H}(U)$. Jika $\alpha \in \widetilde{h}$, maka $\alpha$ adalah suatu bilangan kabur intuisionistik bernilai interval (IVIFN), dan dinotasikan $\alpha=\left(\left[\mu_{\alpha}^{-}, \mu_{\alpha}^{+}\right],\left[\nu_{\alpha}^{-}, \nu_{\alpha}^{+}\right]\right)$.

Teorema 2.4. [4] Misalkan $\tilde{h}, \tilde{h}_{1}, \tilde{h}_{2}$ merupakan tiga elemen kabur intuisionistik hesitant bernilai interval (IVIHFE), dan $\lambda, \lambda_{1}, \lambda_{2}>0$. Maka yang berikut berlaku:

(1) ${\tilde{h_{1}}}^{c} \cup{\tilde{h_{2}}}^{c}=\left(\tilde{h_{1}} \cap \tilde{h_{2}}\right)^{c}$.

(2) ${\tilde{h_{1}}}^{c} \cap{\tilde{h_{2}}}^{c}=\left(\tilde{h_{1}} \cup \tilde{h_{2}}\right)^{c}$. 
(3) ${\widetilde{h_{1}}}^{c} \oplus \widetilde{h_{2}}{ }^{c}=\left(\tilde{h_{1}} \otimes \widetilde{h_{2}}\right)^{c}$.

(4) $\tilde{h_{1}}{ }^{c} \otimes{\tilde{h_{2}}}^{c}=\left(\tilde{h_{1}} \oplus \tilde{h_{2}}\right)^{c}$.

(5) $\left(\tilde{h}^{c}\right)^{\lambda}=(\lambda \tilde{h})^{c}$.

(6) $\lambda\left(\tilde{h^{c}}\right)=\left(\tilde{h}^{\lambda}\right)^{c}$.

(7) $\left.\tilde{h}^{\lambda_{1} \lambda_{2}}=\tilde{\left(h^{\lambda_{1}}\right.}\right)^{\lambda_{2}}$

(8) $\lambda_{1} \lambda_{2}(\tilde{h})=\lambda_{1}\left(\lambda_{2} \tilde{h}\right)$.

(9) $\lambda\left(\tilde{h_{1}} \oplus \tilde{h_{2}}\right)=\lambda \tilde{h_{1}} \oplus \lambda \tilde{h_{2}}$.

(10) $\tilde{h_{1}}{ }^{\lambda} \otimes{\tilde{h_{2}}}^{\lambda}=\left(\tilde{h_{1}} \otimes \tilde{h_{2}}\right)^{\lambda}$.

Definisi 2.5. [4] Misalkan $\tilde{h}$ suatu elemen kabur intuisionistik hesitant bernilai interval (IVIHFE), maka fungsi skor dari $\tilde{h}$ yaitu $S(\tilde{h})=\frac{\sum_{a \in \tilde{h}} T(\alpha)}{l_{\tilde{h}}}$ dengan $l_{\tilde{h}}$ adalah banyak anggota di $\tilde{h}$.

\section{Pembahasan}

Himpunan lembut kabur intuisionistik hesitant bernilai interval merupakan penggabungan dari teori himpunan kabur intuisionistik hesitant bernilai interval dan teori himpunan lembut.

\subsection{Himpunan Lembut Kabur Intuisionistik Hesitant Bernilai Interval}

Definisi 3.1. [3] Misalkan $U$ adalah himpunan semesta, dan $E$ adalah himpunan parameter. Suatu pasangan $(\tilde{F}, A)$ disebut himpunan lembut kabur intuisionistik hesitant bernilai interval atas $U$, dengan $\widetilde{F}$ adalah suatu pemetaan dari A ke $\tilde{H}(U)$, dimana $\tilde{H}(U)$ adalah himpunan dari seluruh himpunan kabur intuisionistik hesitant bernilai interval atas $U$, dan $A \subseteq E$. Himpunan $(\tilde{F}, A)$ dapat ditulis sebagai:

$$
(\tilde{F}, A)=\left\{\left\langle e_{i}, \tilde{F}\left(e_{i}\right)\right\rangle \mid \tilde{F}\left(e_{i}\right) \in \tilde{H}(U), e_{i} \in A\right\},
$$

dengan $\tilde{F}\left(e_{i}\right)=\left\{\left\langle x, \mu_{\widetilde{F}\left(e_{i}\right)}(x), \nu_{\widetilde{F}\left(e_{i}\right)}(x)\right\rangle \mid x \in U, e_{i} \in A\right\}$, dan $\mu_{\widetilde{F}\left(e_{i}\right)}(x), \nu_{\widetilde{F}\left(e_{i}\right)}(x)$ berturut-turut menyatakan derajat keanggotaan dan derajat ketidakanggotaan dari $x \in U$ pada himpunan $(\tilde{F}, A)$.

Definisi 3.2. [3] Misalkan U adalah himpunan semesta dan E suatu himpunan parameter, $A \subseteq E$ dan $B \subseteq E$. Himpunan $(\tilde{F}, A)$ dan $(\tilde{G}, B)$ adalah dua himpunan lembut kabur intuisionistik hesitant bernilai interval. Himpunan $(\tilde{G}, B)$ disebut himpunan bagian lembut kabur intuisionistik hesitant bernilai interval dari $(\widetilde{F}, A)$, yang $\operatorname{dinotasikan}(\tilde{F}, A) \supseteq(\widetilde{G}, B)$ jika:

(1) $A \supseteq B$; 
(2) $\forall e \in B, x \in U, S\left(h_{\widetilde{F}(e)}(x)\right) \geq S\left(h_{\widetilde{G}(e)}(x)\right)$.

Definisi 3.3. [3] Himpunan lembut kabur intuisionistik hesitant bernilai interval $(\tilde{F}, A)$ atas $U$, dikatakan himpunan lembut kabur intuisionistik hesitant bernilai interval kosong (empty) jika $\forall e \in A, \widetilde{F}(e)=\{[0,0],[1,1]\}$ dan dinotasikan dengan $\widetilde{\Phi}_{A}$. Himpunan lembut kabur intuisionistik hesitant bernilai interval $(\tilde{F}, A)$ atas $U$, dikatakan himpunan lembut kabur intuisionistik hesitant bernilai interval penuh (full) jika $\forall e \in A, \tilde{F}(e)=\{[1,1],[0,0]\}$ dan dinotasikan dengan $\tilde{U}_{A}$.

\subsection{Operasi-operasi Himpunan Lembut Kabur Intuisionistik Hesitant Bernilai Interval}

Berikut akan dijelaskan definisi dari beberapa operasi-operasi pada himpunan lembut kabur intuisionistik hesitant bernilai interval.

Definisi 3.4. [3] Komplemen dari himpunan lembut kabur intuisionistik hesi-tant bernilai interval $(\tilde{F}, A)$, yang dinotasikan dengan $(\tilde{F}, A)^{c}$, didefinisikan sebagai $(\tilde{F}, A)^{c}=\left(\tilde{F^{c}}, A\right)$ dimana $\tilde{F}^{c}: A \rightarrow \widetilde{H}(U)$ merupakan pemetaan yang didefinisikan oleh $\tilde{F}^{c}(e)=(\tilde{F}(e))^{c}, \forall e \in A$.

Definisi 3.5. [3] Suatu operasi "AND" pada himpunan lembut kabur intuisio-nistik hesitant bernilai interval dari $(\widetilde{F}, A)$ dan $(\tilde{G}, B)$ yang dinotasikan dengan $(\widetilde{F}, A) \wedge$ $(\tilde{G}, B)$, dapat didefinisikan sebagai:

$$
(\widetilde{F}, A) \wedge(\widetilde{G}, B)=(\widetilde{H}, A \times B),
$$

dimana $\tilde{H}(\alpha, \beta)=\tilde{F}(\alpha) \cap \widetilde{G}(\beta), \forall(\alpha, \beta) \in A \times B$, dan $\tilde{H}(\alpha, \beta)(x)=\left\{\left(\left[\inf \left(\underline{\mu}_{\tilde{f}(\alpha)}(x)\right.\right.\right.\right.$, $\left.\left.\left.\underline{\mu}_{\tilde{g}(\beta)}(x)\right), \inf \left(\bar{\mu}_{\tilde{f}(\alpha)}(x), \bar{\mu}_{\tilde{g}(\beta)}(x)\right)\right],\left[\sup \left(\underline{\nu}_{\tilde{f}(\alpha)}(x), \underline{\nu}_{\tilde{g}(\beta)}(x)\right), \sup \left(\bar{\nu}_{\tilde{f}(\alpha)}(x), \bar{\nu}_{\tilde{g}(\beta)}(x)\right)\right]\right)$ $\mid \tilde{f}(\alpha)(x) \in \tilde{F}(\alpha)(x), \tilde{g}(\beta)(x) \in \tilde{G}(\beta)(x)\}$.

Definisi 3.6. [3] Suatu operasi "OR" pada himpunan lembut kabur intuisionistik hesitant bernilai interval dari $(\tilde{F}, A)$ dan $(\tilde{G}, B)$ yang dinotasikan dengan $(\tilde{F}, A) \vee$ $(\tilde{G}, B)$, dapat didefinisikan sebagai:

$$
(\tilde{F}, A) \vee(\tilde{G}, B)=(\tilde{O}, A \times B),
$$

$\operatorname{dimana} \tilde{O}(\alpha, \beta)=\tilde{F}(\alpha) \cup \widetilde{G}(\beta), \forall(\alpha, \beta) \in A \times B$, dan $\widetilde{O}(\alpha, \beta)(x)=\left\{\left(\left[\sup \left(\underline{\mu}_{\tilde{f}(\alpha)}(x)\right.\right.\right.\right.$, $\left.\left.\left.\underline{\mu}_{\tilde{g}(\beta)}(x)\right), \sup \left(\bar{\mu}_{\tilde{f}(\alpha)}(x), \bar{\mu}_{\tilde{g}(\beta)}(x)\right)\right],\left[\inf \left(\underline{\nu}_{\tilde{f}(\alpha)}(x), \underline{\nu}_{\tilde{g}(\beta)}(x)\right), \inf \left(\bar{\nu}_{\tilde{f}(\alpha)}(x), \bar{\nu}_{\tilde{g}(\beta)}(x)\right)\right]\right)$ $\mid \tilde{f}(\alpha)(x) \in \tilde{F}(\alpha)(x), \tilde{g}(\beta)(x) \in \tilde{G}(\beta)(x)\}$.

Teorema 3.7. [3] (Hukum De Morgan) Misalkan $(\tilde{F}, A)$ dan $(\tilde{G}, B)$ adalah dua himpunan lembut kabur intuisionistik hesitant bernilai interval atas $U$, maka :

(1) $((\tilde{F}, A) \wedge(\tilde{G}, B))^{c}=(\tilde{F}, A)^{c} \vee(\tilde{G}, B)^{c}$. 
(2) $((\tilde{F}, A) \vee(\tilde{G}, B))^{c}=(\tilde{F}, A)^{c} \wedge(\tilde{G}, B)^{c}$.

Teorema 3.8. [3] (Hukum Assosiatif) Misalkan $(\tilde{F}, A),(\tilde{G}, B)$, dan $(\tilde{H}, C)$ adalah tiga himpunan lembut kabur intuisionistik hesitant bernilai interval atas $U$, maka :

(1) $(\tilde{F}, A) \wedge((\tilde{G}, B) \wedge(\tilde{H}, C))=((\tilde{F}, A) \wedge(\widetilde{G}, B)) \wedge(\tilde{H}, C)$.

(2) $(\tilde{F}, A) \vee((\tilde{G}, B) \vee(\tilde{H}, C))=((\tilde{F}, A) \vee(\tilde{G}, B)) \vee(\tilde{H}, C)$.

Definisi 3.9. [3] Gabungan dari dua himpunan lembut kabur intuisionistik hesitant bernilai interval yang dinotasikan dengan $(\tilde{F}, A) \tilde{\cup}(\tilde{G}, B)=(\tilde{H}, C)$ dimana $C=$ $A \cup B$ dan $\forall e \in C$ berlaku:

$$
\tilde{H}(e)= \begin{cases}\tilde{F}(e), & \text { jika } e \in A-B, \\ \tilde{G}(e), & \text { jika } e \in B-A, \\ \tilde{F}(e) \cup \tilde{G}(e), & \text { jika } e \in A \cap B .\end{cases}
$$

Teorema 3.10. [3] Misalkan $(\tilde{F}, A)$ dan $(\tilde{G}, B)$ adalah dua himpunan lembut kabur intuisionistik hesitant bernilai interval atas $U$, maka:

(1) $(\tilde{F}, A) \tilde{\cup}(\tilde{F}, A)=(\tilde{F}, A)$.

(2) $(\tilde{F}, A) \widetilde{\cup} \tilde{\Phi}_{A}=(\tilde{F}, A)$.

(3) $(\tilde{F}, A) \tilde{\cup} \tilde{U}_{A}=\tilde{U}_{A}$.

(4) $(\tilde{F}, A) \tilde{\cup} \tilde{U}_{B}=\tilde{U}_{B}$ jika dan hanya jika $A \subseteq B$.

(5) $(\tilde{F}, A) \widetilde{\cup} \tilde{\Phi}_{B}=(\tilde{F}, A)$ jika dan hanya jika $B \subseteq A$.

(6) $(\tilde{F}, A) \tilde{\cup}(\widetilde{G}, B)=(\widetilde{G}, B) \tilde{\cup}(\tilde{F}, A)$.

\section{Bukti.}

(1) Akan dibuktikan $(\tilde{F}, A) \tilde{\cup}(\tilde{F}, A)=(\tilde{F}, A)$.

Berdasarkan Definisi (3.15), misalkan $(\tilde{F}, A) \tilde{\cup}(\tilde{F}, A)=(\tilde{H}, C)$, dimana $C=A \cup$ $A=A$ dan $\forall e \in C$, diperoleh $\tilde{H}(e)=\tilde{F}(e) \cup \tilde{F}(e)=\tilde{F}(e)$. Karena untuk setiap $e \in C, \widetilde{H}(e)=\widetilde{F}(e)$, maka dapat disimpulkan bahwa $(\tilde{F}, A) \tilde{\cup}(\tilde{F}, A)=(\tilde{F}, A)$.

(2) Untuk pembuktian (2) - (6), sama seperti pembuktian nomor (1).

Definisi 3.11. [3] Irisan dari dua himpunan lembut kabur intuisionistik hesitant bernilai interval yang dinotasikan dengan $(\tilde{F}, A) \tilde{\cap}(\tilde{G}, B)=(\tilde{H}, C)$, dimana $C=$ $A \cap B$ dan $\forall e \in C$, berlaku $\tilde{H}(e)=\tilde{F}(e) \cap \tilde{G}(e)$.

Teorema 3.12. [3] Misalkan $(\tilde{F}, A)$ dan $(\tilde{G}, B)$ adalah dua himpunan lembut kabur intuisionistik hesitant bernilai interval atas $U$, maka :

(1) $(\tilde{F}, A) \tilde{\cap}(\tilde{F}, A)=(\tilde{F}, A)$.

(2) $(\tilde{F}, A) \tilde{\cap} \widetilde{\Phi}_{A}=\widetilde{\Phi}_{A}$. 
(3) $(\tilde{F}, A) \tilde{\cap} \tilde{U}_{A}=(\tilde{F}, A)$.

(4) $(\tilde{F}, A) \tilde{\cap} \widetilde{U}_{B}=(\tilde{F}, A \cap B)$.

(5) $(\tilde{F}, A) \tilde{\cap} \widetilde{\Phi}_{B}=\widetilde{\Phi}_{A \cap B}$.

(6) $(\tilde{F}, A) \tilde{\cap}(\widetilde{G}, B)=(\widetilde{G}, B) \tilde{\cap}(\tilde{F}, A)$.

Definisi 3.13. [3] Gabungan restricted dari dua himpunan lembut kabur intuisionistik hesitant bernilai interval yang dinotasikan dengan $(\tilde{F}, A) \tilde{\cup}_{R}(\tilde{G}, B)=$ $(\tilde{H}, C)$, dimana $C=A \cap B$ dan $\forall e \in C$, berlaku $\tilde{H}(e)=\tilde{F}(e) \cup \widetilde{G}(e)$.

Teorema 3.14. [3] Misalkan $(\tilde{F}, A)$ dan $(\tilde{G}, B)$ adalah dua himpunan lembut kabur intuisionistik hesitant bernilai interval atas $U$, maka :

(1) $(\tilde{F}, A) \tilde{\cup}_{R}(\tilde{F}, A)=(\tilde{F}, A)$.

(2) $(\tilde{F}, A) \tilde{\cup}_{R} \widetilde{\Phi}_{A}=(\tilde{F}, A)$.

(3) $(\tilde{F}, A) \tilde{\cup}_{R} \tilde{U}_{A}=\tilde{U}_{A}$.

(4) $(\tilde{F}, A) \tilde{\cup}_{R} \tilde{U}_{B}=\tilde{U}_{A \cap B}$.

(5) $(\tilde{F}, A) \tilde{\cup}_{R} \tilde{\Phi}_{B}=(\tilde{F}, A \cap B)$.

(6) $(\tilde{F}, A) \tilde{\cup}_{R}(\tilde{G}, B)=(\tilde{G}, B) \tilde{\cup}_{R}(\tilde{F}, A)$.

Definisi 3.15. [3] Irisan extended dari dua himpunan lembut kabur intuisionistik hesitant bernilai interval yang dinotasikan dengan $(\tilde{F}, A) \tilde{\cap}_{E}(\tilde{G}, B)=(\tilde{H}, C)$, dimana $C=A \cup B$ dan $\forall e \in C$, berlaku :

$$
\tilde{H}(e)= \begin{cases}\tilde{F}(e), & \text { jika } e \in A-B, \\ \widetilde{G}(e), & \text { jika } e \in B-A, . \\ \tilde{F}(e) \cap \tilde{G}(e), & \text { jika } e \in A \cap B .\end{cases}
$$

Teorema 3.16. [3] Misalkan $(\tilde{F}, A)$ dan $(\tilde{G}, B)$ adalah dua himpunan lembut kabur intuisionistik hesitant bernilai interval atas $U$, maka :

(1) $(\tilde{F}, A) \tilde{\cap}_{E}(\tilde{F}, A)=(\tilde{F}, A)$.

(2) $(\tilde{F}, A) \tilde{\cap}_{E} \widetilde{\Phi}_{A}=\widetilde{\Phi}_{A}$.

(3) $(\tilde{F}, A) \tilde{\cap}_{E} \tilde{U}_{A}=(\tilde{F}, A)$.

(4) $(\tilde{F}, A) \tilde{\cap}_{E} \tilde{U}_{B}=(\tilde{F}, A)$ jika dan hanya jika $B \subseteq A$.

(5) $(\tilde{F}, A) \tilde{\cap}_{E} \widetilde{\Phi}_{B}=\widetilde{\Phi}_{B}$ jika dan hanya jika $A \subseteq B$.

(6) $(\tilde{F}, A) \tilde{\cap}_{E}(\widetilde{G}, B)=(\widetilde{G}, B) \tilde{\cap}_{E}(\tilde{F}, A)$.

Teorema 3.17. [3] Misalkan $(\tilde{F}, A),(\tilde{G}, B)$, dan $(\tilde{H}, C)$ adalah tiga himpunan lembut kabur intuisionistik hesitant bernilai interval atas $U$, maka :

(1) $(\tilde{F}, A) \tilde{\cap}_{E}\left((\tilde{G}, B) \tilde{\cap}_{E}(\tilde{H}, C)\right)=\left((\tilde{F}, A) \tilde{\cap}_{E}(\tilde{G}, B)\right) \tilde{\cap}_{E}(\tilde{H}, C)$.

(2) $(\tilde{F}, A) \tilde{\cup}((\tilde{G}, B) \tilde{\cup}(\tilde{H}, C))=((\tilde{F}, A) \tilde{\cup}(\tilde{G}, B)) \tilde{\cup}(\tilde{H}, C)$. 
Definisi 3.18. [3] Misalkan $(\widetilde{F}, A)$ adalah himpunan lembut kabur intuisionistik hesitant bernilai interval atas U. Operasi " power- $\lambda$ " pada himpunan lembut kabur intuisionistik hesitant bernilai interval didefinisikan :

$$
(\tilde{F}, A)^{\lambda}=\left\{\tilde{F^{\lambda}}(e) \mid e \in A\right\}
$$

$\operatorname{dimana} \tilde{F}^{\lambda}(e)=\left\{\tilde{h}_{\tilde{F}(e)}^{\lambda}(x) \mid x \in U, \lambda>0\right\}$.

Definisi 3.19. [3] Misalkan $(\widetilde{F}, A)$ adalah himpunan lembut kabur intuitionistik hesitant bernilai interval atas $U$. Operasi " $\lambda$-multiply " pada himpunan lembut kabur intuisionistik hesitant bernilai interval didefinisikan :

$$
\lambda(\tilde{F}, A)=\{\lambda \widetilde{F}(e) \mid e \in A\},
$$

$\operatorname{dimana} \lambda \tilde{F}(e)=\left\{\lambda \tilde{h}_{\tilde{F}(e)}(x) \mid x \in U, \lambda>0\right\}$.

Teorema 3.20. Misalkan $(\tilde{F}, A)$ adalah himpunan lembut kabur intuitionis-tik hesitant bernilai interval atas $U, \lambda>0$, dan $\lambda_{1}>0$ maka:

(1) $\left((\tilde{F}, A)^{c}\right)^{\lambda}=(\lambda(\tilde{F}, A))^{c}$.

(2) $\lambda\left((\tilde{F}, A)^{c}\right)=\left((\tilde{F}, A)^{\lambda}\right)^{c}$.

(3) $(\widetilde{F}, A)^{\lambda \lambda_{1}}=\left((\tilde{F}, A)^{\lambda}\right)^{\lambda_{1}}$.

(4) $\left(\lambda \lambda_{1}\right)(\tilde{F}, A)=\lambda\left(\lambda_{1}(\tilde{F}, A)\right)$.

\section{Bukti.}

(1) Akan dibuktikan $\left((\tilde{F}, A)^{c}\right)^{\lambda}=(\lambda(\tilde{F}, A))^{c}$. Misalkan $(\tilde{F}, A)=\{\langle e, \tilde{F}(e)\rangle \mid e \in$ $A\}$. Karena $\left((\tilde{F}, A)^{c}\right)^{\lambda}=\left(\tilde{F}^{c}, A\right)^{\lambda}$, maka $\forall e \in A,\left((\tilde{F}, A)^{c}\right)^{\lambda}=\left(\tilde{F}^{c}(e)\right)^{\lambda}$. Berdasarkan Teorema (2.4), diperoleh $\left(\tilde{F}^{c}(e)\right)^{\lambda}=(\lambda \tilde{F}(e))^{c}$. Oleh karena $(\lambda \tilde{F}(e))^{c}=(\lambda(\tilde{F}, A))^{c}$, maka dapat disimpulkan bahwa $\left((\tilde{F}, A)^{c}\right)^{\lambda}=(\lambda(\tilde{F}, A))^{c}$. () Untuk pembuktian (2) -(4), hampir sama dengan pembuktian pada nomor $1 . \square$

Definisi 3.21. [3] Operasi" Average " pada dua himpunan lembut kabur intuisionistik hesitant bernilai interval $(\widetilde{F}, A)$ dan $(\tilde{G}, B)$ atas $U$, dinotasikan oleh $(\tilde{F}, A)$ $\oplus(\widetilde{G}, B)$, dan didefinisikan :

$$
(\tilde{F}, A) \oplus(\tilde{G}, B)=(\tilde{H}, A \times B),
$$

dimana $\tilde{H}(\alpha, \beta)=\tilde{F}(\alpha) \oplus \tilde{G}(\beta), \forall(\alpha, \beta) \in A \times B$.

Definisi 3.22. [3] Operasi " Geometri " pada dua himpunan lembut kabur intuisionistik hesitant bernilai interval $(\tilde{F}, A)$ dan $(\tilde{G}, B)$ atas $U$, dinotasikan oleh $(\tilde{F}, A)$ $\otimes(\widetilde{G}, B)$, dan didefinisikan :

$$
(\tilde{F}, A) \otimes(\tilde{G}, B)=(\widetilde{O}, A \times B),
$$


$\operatorname{dimana} \widetilde{O}(\alpha, \beta)=\widetilde{F}(\alpha) \otimes \widetilde{G}(\beta), \forall(\alpha, \beta) \in A \times B$

Teorema 3.23. [3] (Hukum De Morgan) Misalkan $(\tilde{F}, A)$ dan $(\tilde{G}, B)$ adalah dua himpunan lembut kabur intuisionistik hesitant bernilai interval atas $U$, maka:

(1) $((\tilde{F}, A) \oplus(\tilde{G}, B))^{c}=(\tilde{F}, A)^{c} \otimes(\tilde{G}, B)^{c}$.

(2) $((\tilde{F}, A) \otimes(\widetilde{G}, B))^{c}=(\tilde{F}, A)^{c} \oplus(\tilde{G}, B)^{c}$.

\section{Kesimpulan}

Berdasarkan pembahasan maka dapat disimpulkan bahwa himpunan lembut kabur intuisionistik hesitant bernilai interval adalah penggabungan dari himpunan kabur intuisionistik hesitant bernilai interval dengan himpunan lembut. Pada himpunan lembut kabur intuisionistik hesitant bernilai interval, terdapat beberapa operasioperasi seperti AND, OR, gabungan, irisan, dsb. Dari gabungan atau irisan tersebut, maka akan berlaku beberapa sifat assosiatif. Selain itu, juga terdapat beberapa operasi lain seperti average dan geometric.

\section{Ucapan Terima kasih}

Penulis mengucapkan terima kasih kepada bapak Dr. Admi Nazra dan bapak Dr. Mahdhivan Syafwan selaku dosen pembimbing yang telah membantu penulis dalam menyelesaikan makalah ini. Dan juga terima kasih kepada ibu Dr. Yanita, ibu Riri Lestari, M.Si, bapak Budi Rudianto M.Si selaku dosen penguji yang telah memberikan masukan dan saran sehingga makalah ini dapat diselesaikan dengan baik.

\section{Daftar Pustaka}

[1] Atanassov, K. dan Gargov, G. 1989. Interval-valued intuitionistic fuzzy sets. Fuzzy Sets and Systems. 31(3): $343-349$.

[2] Xu, Z. 2007. Methods for aggregating interval-valued intuitionstic fuzzy information and their application to decision making. Control and Decision. 22: 215 $-219$.

[3] Yang, Y. dan Peng, X.D. 2015. Approaches to interval-valued intuitionistic hesitant fuzzy soft sets based decision making. Ann. Fuzzy Math. Inform. 10(10): $1-20$.

[4] Zhang, Z.M. 2013. Interval-Valud Intuitionistic Hesitant Fuzzy Aggregation Operators and Their Application in Group Decision Making. J. Appl. Math.: 1 33 . 